\title{
A PRACTICAL TEST OF THE ACCURACY OF FOREST-FIRE HAZARD CHARTS
}

\author{
H. W. BEALL \\ Forest Service-Department of the Interior
}

INTRODUCTION

$\mathrm{T}$

HERE are at least two ways in which a check may be obtained on the accuracy of forest-fire hazard charts computed from weather observations. The first and more direct method is to compare the hazard indicated by the chart from day to day with actual duff moisture contents, or with the behaviour of small test fires. A check of this nature has been carried on for two years with charts computed from J. G. Wright's "Forest-Fire Hazard Tables for Mixed Red and White Pine Forests," in which it has been found that the charts are correct to the nearest zone 85 per cent. of the time, and are not more than one zone out $99^{+}$per cent. of the time.

The second method affords, in some ways, a more practical criterion. It consists in comparing the occurrence of actual fires (classified as to origin, size, forest type, distance from observation stations, etc.) with the degree of hazard indicated by the chart when the fires started. A fire starting in "nil" hazard, or a large fire occurring under continued conditions of "low" hazard indicates an error in the chart. By this method two points may be determined: first, the accuracy of the chart in indicating fire occurrence within the area in which weather conditions are similar to those at the observation station; second, the loss in accuracy which results from differences in weather conditions as the distance between the fire and the observation station increases.

A comparison of this nature was carried out with fire-hazard charts prepared at the Petawawa Forest Experiment Station of the Dominion Forest Service, Department of the Interior, at Chalk River, Ontario. The charts used were for mixed red and white pine, fast-drying sites, and were computed from the tables mentioned above. The fire data used, supplied through the courtesy of Messrs. F. A. MacDougall and E. L. Ward, of the Ontario Forestry Branch, covered the fires occurring in the Algonquin District of that organization during the years 1929 to 1933. The period taken in each year was from about the middle of May to the middle of October, but varied somewhat in different years according to the weather data available for computing the charts at the Petawawa Station. In all, 716 days, with 365 fires, were included.

The Algonquin District comprises roughly 5,500 square miles, with the Petawawa Station near the north-east corner. All fires occurred within a radius of 100 miles from the Station. The topography throughout the area 
is generally quite similar to that at the Petawawa Station, but is perhaps a little more hilly in some portions.

Although the charts used were designed for a particular forest type, fires in all types were used in the comparison. Fires occurring in open areas, including grass, barren or muskeg, cleared land, and recent burns were classified separately in the analysis, but it was found that their occurrence coincided so well, as far as degree of hazard was concerned, with those in forested areas that it was not considered worth while to separate them in the final summary. Fires were classified as to size in two groups- $1 / 4$ acre and

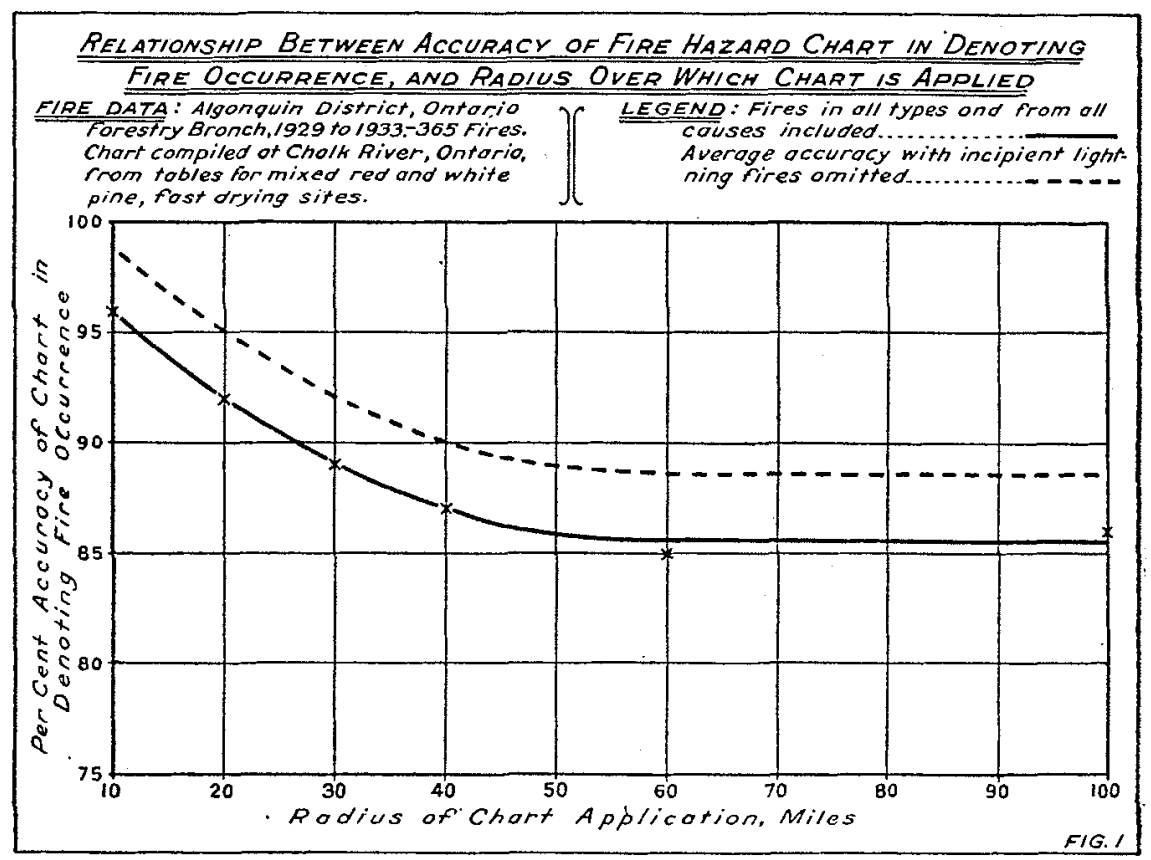

less, and over $1 / 4$ acre. They were also grouped into seven zones according to distance from the Petawawa station.

Table I shows the number of fires starting in each degree of hazard, in each size-class, and in each distance zone.

ACCURACY OF CHARTS FOR FIRES WITHIN RANGE OF WEATHER CONDITIONS PREVAILING AT THE PETAWAWA STATION

A glance at Table I.. shows that the considerable total of 52 fires started when a condition of "nil" hazard was indicated by the chart. The circum. stances attending each of these fires were carefully investigated, resulting in the further classification shown in Table II. 


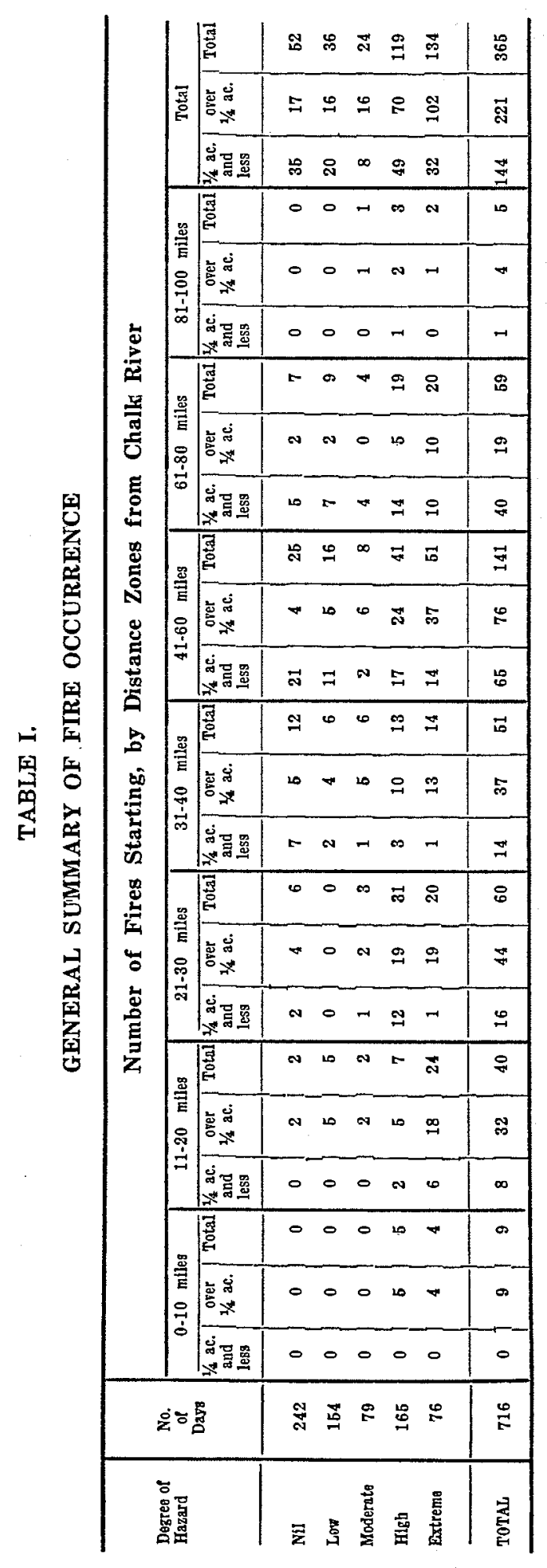


FOREST FIRE HAZARD CHARTS-BEALL

TABLE II.

Summary of Fires Starting in "Nil" Hazard

\begin{tabular}{|c|c|c|c|}
\hline \multirow[b]{2}{*}{ Circumstances Attending Fire } & \multicolumn{3}{|c|}{ Number of Fires } \\
\hline & $\begin{array}{l}1 / 4 \text { acre } \\
\text { or less }\end{array}$ & $\begin{array}{l}1 / 4 \text { acre } \\
\text { over }\end{array}$ & Total \\
\hline $\begin{array}{l}\text { Fires where evidence indicates that drier con- } \\
\text { ditions existed at scene of fire than at Chalk } \\
\text { River, due to rainfall difference }\end{array}$ & 21 & 15 & 36 \\
\hline $\begin{array}{l}\text { Fires started by lightning, where evidence in- } \\
\text { dicates similar weather conditions to those at } \\
\text { Chalk River }\end{array}$ & 10 & 0 & 10 \\
\hline $\begin{array}{l}\text { Fires started from camp-fires where evidence } \\
\text { indicates similar weather conditions to those } \\
\text { at Chalk River }\end{array}$ & 0 & 1 & 1 \\
\hline $\begin{array}{l}\text { Fires where no evidence is available for com- } \\
\text { paring weather conditions with those at Chalk } \\
\text { River }\end{array}$ & 4 & 1 & 5 \\
\hline TOTAL & 35 & 17 & 52 \\
\hline
\end{tabular}

It will be observed that two-thirds of the fires fall in the first group, that is, they occurred under weather conditions known to be drier than those then prevailing at the point where the charts were computed. Rainfall records from various rangers' stations in the Algonquin District, and from the town of Pembroke, were used in making this check. Fires which started on the same day that rain fell, but before the rain began, and which were put out by the rain, were included in this group. Obviously these fires do not indicate an inherent error in the chart method, since, if a sufficient number of stations equipped to prepare charts had been established in the area, allowance would have been made for the rainfall variations in each part of the District.

With reference to lightning fires it is well known that, even after the heaviest rains, lightning striking a stump or log may cause the interior to ignite and continue to burn or smoulder for some time. It is practically impossible to allow for such fires in an inflammability chart of this nature. The assertion is confidently made, however, that such fires will not spread over the forest floor as long as the chart indicates "nil" hazard, and provided that the observation station is sufficiently close to be representative of weather conditions at the fire. If dry weather follows, the fire may spread in the litter as soon as hazard rises. The ten lightning fires included in the second group of Table II. were all very small, and mostly confined to single trees.

The single fire in the third group started from a camp-fire under conditions of "nil" hazard according to the chart. There are several possible 
extenuating circumstances connected with this, fire:, it occurred in a different forest type from that for which the charts were prepared; it was not discovered for three days after starting, by which time the hazard had risen to "high;" the total area covered was only one acre. It is very probable that the camp-fire continued to smoulder through the period of "nil" hazard, possibly in underground roots, and did not spread until drier conditions prevailed. In any event, this is the only fire out of the 365 (apart from the 10 small lightning fires) in which the evidence indicates an error in the chart's record of the hazard.

The five fires in the last group occurred on days when there is doubt as to the agreement of weather conditions with those at the Petawawa station.

The 16 fires larger than $1 / 4$ acre starting in "low" hazard were similarly investigated. Most of these were found to have been followed by two or more days of dry weather during which the fires were able to spread. They are, therefore, quite in agreement with the chart records. The remainder occurred under drier conditions than those at the Petawawa station.

A summary of the accuracy of the fire hazard charts, expressed percentically, is given in Table III.

TABLE III.

Summary of Chart Accuracy with Respect to Fire Occurrence

\begin{tabular}{|c|c|c|}
\hline Data Included & $\begin{array}{c}\text { No. of Fires } \\
\text { Included }\end{array}$ & $\begin{array}{l}\text { Per cent. } \\
\text { Accuracy }\end{array}$ \\
\hline (a) All fires included & 365 & 85.2 \\
\hline $\begin{array}{l}\text { (b) Fires omitted where error known to } \\
\text { be due to difference in rainfall } \\
\text { between Chalk River and area con- } \\
\text { cerned }\end{array}$ & 327 & 95.2 \\
\hline $\begin{array}{l}\text { (c) Same as (b), with fires also omitted } \\
\text { where doubt exists as to agreement } \\
\text { of weather conditions at Chalk } \\
\text { River with those at area concerned }\end{array}$ & 322 & 96.6 \\
\hline $\begin{array}{l}\text { (d) Same as (c), with lightning fires } \\
\text { of less than } 1 / 4 \text { acre also omitted }\end{array}$ & 312 & 99.7 \\
\hline
\end{tabular}

The accuracy of the chart for fires within the range of weather conditions prevailing at the Petawawa station was $95.2 \%$, plus a possible $1.4 \%$ attributable to doubtful cases. It is thus seen that charts prepared from the mixed red and white pine tables give an excellent indication of fires occurring from all causes and in all types, including open areas. When incipient lightning fires are excluded, the accuracy is well-nigh perfect. 
Two other points derived from the data are worthy of passing mention.

By finding the ratio:-

Total number of days

Total number of fires occurring in each degree of hazard.

we obtain an expression which relates average fire risk to degree of hazard. This may be useful in comparing fire risk in different areas. The figures for the Algonquin District are shown in Table IV, and include all fires except those known to occur under different weather conditions from those at the Petawawa station.

TABLE IV.

Probability of Fire Occurrence, in Relation to Days of Hazard Indicated

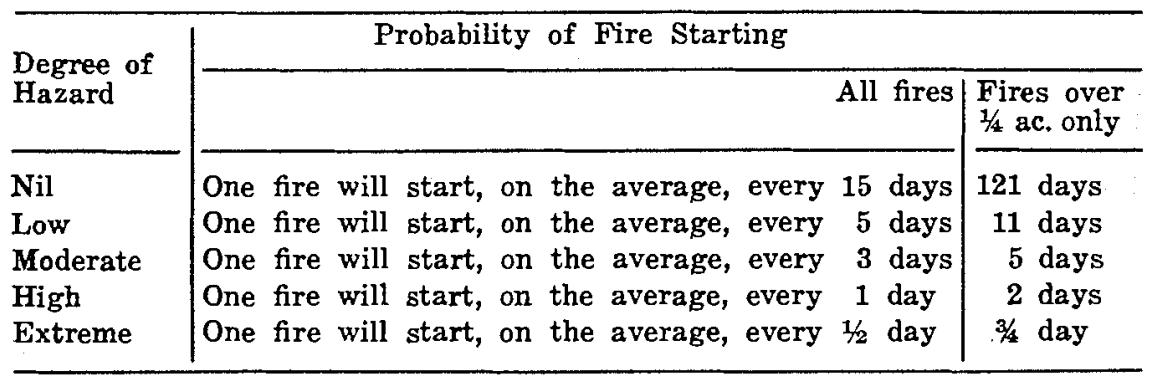

The relative probability of fires starting in the different degrees of hazard is more accurately shown by taking the probability in extreme hazard as 100 and expressing the others in proportion (Table V). It will be noted that the probability of fire occurrence is roughly doubled for each increase of one degree of hazard, when fires of all sizes are considered.

TABLE V.

Relative Probability of Fire Occurrence

\begin{tabular}{l|c|c}
\hline \multirow{2}{*}{ Degree of Hazard } & \multicolumn{2}{|c}{$\begin{array}{c}\text { Probability of Fire Starting } \\
\text { (Extreme=100) }\end{array}$} \\
\cline { 2 - 3 } & All fires & Fires over $1 / 4$ ac. only \\
\hline & 100 & 100 \\
Extreme & 41 & 32 \\
High & 17 & 15 \\
Moderate & 12 & 7 \\
Low & 3 & 0.6 \\
Nil-lightning fires & 1 & \\
Nil-other fires & & \\
\hline
\end{tabular}

In the case of one fire, data were available by which the daily variation in the vigour of burning of a fire could be compared with the daily variation in the chart hazard. This fire started on July 2nd, 1931, near Aylen Lake, about 36 miles from Chalk River. The comparison is shown in Table VI. 
TABLE VI.

Comparison of Daily Variation in Chart Hazard and in Fire Behaviour

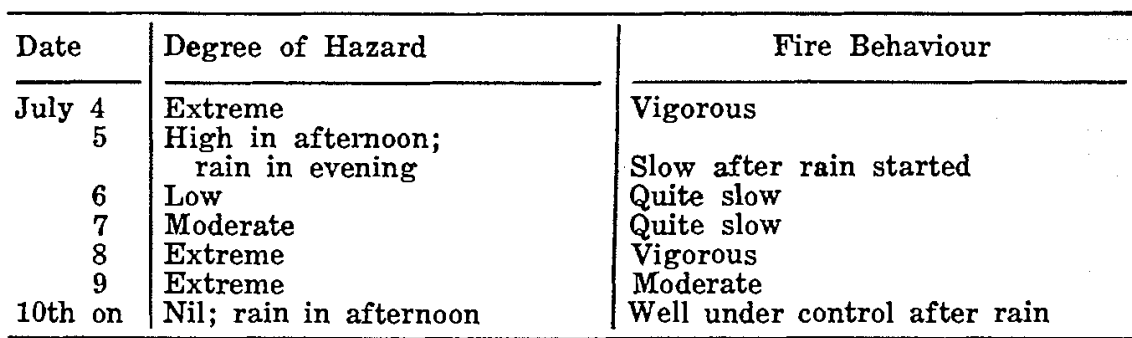

The relationship is very good considering the distance separating the fire from the station, the fact that no data were available regarding the forest types being burned or the disposition of fire-fighting forces.

\section{EFFECTIVE RADIUS OF CHART APPLICATION}

An examination of the data showed that nearly all the variations in the weather elements in the area under consideration that were of sufficient mag. nitude to affect the fire-hazard charts, were directly associated with irregularities in rainfall distribution. The rains accompanying normal areas of low pressure are usually distributed quite uniformly in an area of this size, but thunderstorms tend to follow very localized paths. It is therefore desirable to obtain rainfall records at as many points as possible in any forested area where fire-hazard charts are in use. Even if the installation of rain-gauges at all points is impracticable, a record should be kept of the occurrence of thunderstorms by all forest officers and rangers in the field. By this means the path of each storm, and the area where lightning fires are apt to develop, may be approximately traced.

Since rainfall variations occasion changes in relative humidity and evaporation, it is preferable to install complete equipment for computing firehazard charts at each station where a rain-gauge is located. If this is not practicable, however, a few well-chosen stations for measuring evaporation, rainfall, and relative humidity, with as many auxiliary rainfall stations as possible, should prove quite satisfactory.

In Table VII. the fires occurring in "nil" hazard are expressed as a percentage of the total number of fires, in each distance zone. 
FOREST FIRE HAZARD CHARTS-BEALL

TABLE VII.

Fires Starting in "Nil" Hazard, by Distance Zones

\begin{tabular}{l|c|c|c|c|c|c}
\hline Fires Included & \multicolumn{1}{|c|}{$\begin{array}{c}\text { Fires starting in "Nil" Hazard in each zone, as a } \\
\text { percentage of zone total }\end{array}$} \\
\hline & $\begin{array}{c}0-10 \\
\text { miles }\end{array}$ & $\begin{array}{c}11-20 \\
\text { miles }\end{array}$ & $\begin{array}{c}21-30 \\
\text { miles }\end{array}$ & $\begin{array}{c}31-40 \\
\text { miles }\end{array}$ & $\begin{array}{c}41-60 \\
\text { miles }\end{array}$ & $\begin{array}{c}61-100 \\
\text { miles }\end{array}$ \\
\hline $\begin{array}{l}\text { (a) All fires starting } \\
\text { in "Nil" Hazard }\end{array}$ & 0 & 5 & 10 & 24 & 18 & 11 \\
$\begin{array}{c}\text { (b) Fires starting in } \\
\text { "N i l" Haz a r } \\
\text { known to occur } \\
\text { und e r different } \\
\text { rainfall conditions } \\
\text { from those at } \\
\text { Chalk River }\end{array}$ & 0 & 3 & 7 & 13 & 11 & 3 \\
\hline
\end{tabular}

The figures in Table VII. (b) above afford a better relative measure than those in Table VII. (a) of the decrease in accuracy of the chart as the distances from the weather station increase. They include fires started by light ning storms which are often quite local in nature and may occur anywhere in the area. The apparent increase of accuracy at the greater distances was due mainly to the peculiar conditions accompanying an electrical storm which occurred on July 2nd, 1931. A heavy rainfall was recorded at the weather station, with little or no rain elsewhere in the area, but a large number of lightning fires occurred between 30 and 60 miles from the Petawawa station. In consequence of this erratic distribution, the average chart accuracy is probably slightly underrated between 30 and 60 miles, and overrated at greater distances. However, it is hardly reasonable to expect the chart hazards to be applied over a greater radius than 60 miles, and if we accept the 30 to 60 mile figures as correct for those zones we are at least erring on the safe side.

From the figures in Table VII (b) it is possible to plot a curve showing the probable accuracy of the fire-hazard chart in indicating the occurrence of all fires within any given distance of the weather station up to 100 miles. In plotting this curve (Fig. 1), there was added to the figures in Table VII. (b) a liberal margin of safety of 2 per cent. to cover doubtful cases and the few fires larger than one-quarter acre starting in "low" hazard attributable to rainfall differences. The accuracy of the chart at zero miles (weather station) was taken as 96 per cent. (Table III.)* While the curve shows values up to 100 miles, its reliability above 60 miles is doubtful under conditions of normal lightning-fire distribution.

*By using this figure for the accuracy at the weather station, we make allowance for the fires omitted in Table VII (b), but included in VII (a), starting under slmilar weatber conditions to these at the station. 
While the data on which this curve is based were obtained entirely from the Algonquin District, this curve may be used as a reasonable guide to the accuracy of fire-hazard charts in other areas where the topography is fairly uniform. It is hoped that this information may prove of value to forestprotective organizations in helping them to select stations for the installation of fire-hazard equipment. The facilities available for handling such equipment may be balanced against the degree of accuracy required.

\section{SUMMARY}

An analysis was made of 365 fires occurring in the Algonquin District of the Ontario Forestry Branch during the fire seasons of 1929 to 1933 . The data were used as a practical check on the accuracy of fire-hazard charts prepared for fast-drying sites in the mixed red and white pine type, in indicating fre occurrence. The charts were prepared at the Petawawa Forest Experiment Station of the Dominion Forest Service at Chalk River, Ontario, and all fires occurred within 100 miles of that station. Fires from all causes and in all forest types, as well as in open areas, were included.

The charts were found to possess an accuracy of $96 \pm 1$ per cent. for all fires occurring within the range of weather conditions prevailing at the Petawawa Station. If incipient lightning fires (mostly single trees) are excluded, the accuracy was $99 \pm 1$ per cent.

The decrease of accuracy with increase of distance from the observation station was found to be as follows:

Within 10 miles radius, accuracy for all fires 96 per cent.

Within 20 miles radius, accuracy for all fires 92 per cent.

Within 30 miles radius, accuracy for all fires 89 per cent.

Within 40 miles radius, accuracy for all fires 87 per cent.

Within 60 miles radius, accuracy for all fires 85 per cent.

The relative probability of fires starting in the different degrees of hazard, if the probability in extreme hazard be taken as 100 , was of the following order:-

$\begin{array}{lr}\text { Extreme }, & 100 \\ \text { High , } & 41 \\ \text { Moderate , }, & 17 \\ \text { Low , } & 12 \\ \text { Nil (lightning fires) , , } & 3 \\ \text { Nil (other fires) , } & 1\end{array}$

The probability is roughly doubled for each increase of one degree of hazard. 
In the case of all fires except one, no appreciable spread from the point of origin occurred under conditions of "nil" hazard, irrespective of the starting agency. The exception was a fire concerning which there was no definite information available, and it is very probable that in this case, as in the others, the fire did not spread while the chart hazard remained at "nil."

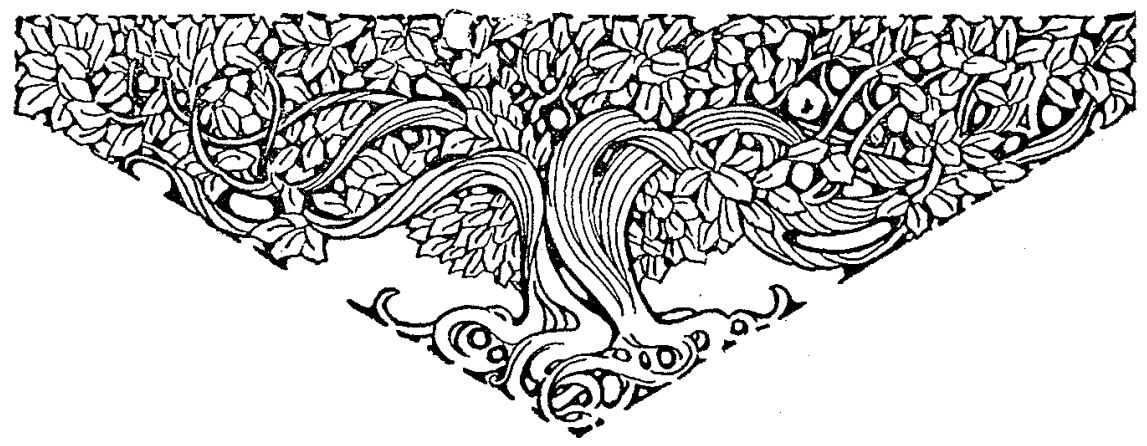

